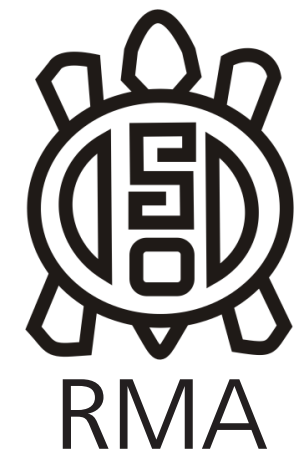

Dossier

\title{
El estudio de los procesos de formación del registro arqueológico y sus efectos en los conjuntos líticos
}

\author{
The study of archaeological record formation processes and their effects
}

on lithic assemblages

Eugenia Carranza*, Catalina Balirán** y Federico Bobillo***

*Instituto Multidisciplinario de Historia y Ciencias Humanas (IMHICIHU - CONICET).

CABA, Argentina. E-mail: carranza.e89@gmail.com

**Facultad de Filosofía y Letras - Universidad de Buenos Aires. CABA, Argentina.

E-mail: cataclorofila@gmail.com

*** Instituto Superior de Estudios Sociales (ISES-CONICET). San Miguel de Tucumán,

Tucumán, Argentina. E-mail: fede_bobillo@yahoo.com.ar

El 1er Congreso Argentino de Estudios Líticos en Arqueología, celebrado en la ciudad de Córdoba en el año 2018, reunió a especialistas de las principales líneas de investigación sobre materiales líticos en la actualidad. De este valioso encuentro nace este volumen especial, que con cada dossier se busca consolidar la propuesta y plasmar los avances en la materia.

El dossier que aquí presentamos tiene como objetivo convocar a las y los autores que participaron del simposio titulado "El estudio de los procesos de formación del registro arqueológico y sus efectos en los conjuntos líticos", y que con sus contribuciones enriquecen el panorama de los estudios sobre la temática. Buscamos reunir especialistas en tecnología lítica que compartan la pregunta acerca de los efectos que los procesos postdepositacionales tienen sobre los conjuntos líticos y sus implicancias en las interpretaciones y explicaciones conductuales sobre los grupos humanos del pasado. En este dossier se presentan estos cuestionamientos y la búsqueda de explicaciones en torno a un problema arqueológico en casos de estudio a lo largo del país, en diferentes contextos y escalas de trabajo.

El estudio de las complejas formas en las que el registro arqueológico puede presentarse ha llevado al desarrollo de una serie de marcos teóricos-metodológicos que se enfocan en las relaciones existentes entre factores culturales, biológicos y físicos. Desde los primeros planteos teóricos metodológicos de la década del '70, y la proliferación y preocupación por este enfoque en los procesos de formación en los '80 en adelante, es una línea de trabajo que sigue vigente, y ha afinado sus preocupaciones, interactuando con otras áreas disciplinares. Estos estudios generan un corpus de datos que permiten afinar las interpretaciones y posibilita acceder a la dinámica del registro arqueológico en el pasado y en la actualidad; evaluando las decisiones y acciones prácticas que los grupos humanos desarrollaron en torno al uso, descarte y reutilización de los materiales arqueológicos.

Desde una perspectiva tafonómica Borrazzo presenta el artículo titulado "Aportes de la Tafonomía actualística al estudio arqueológico de los pseudoartefactos". En este trabajo la autora se propone evaluar el aporte del componente pseudoartefactual en los conjuntos líticos arqueológicos. Toma para ello el caso de estudio el complejo de alero del sitio Casa de Piedra de Roselló, en la provincia de Chubut. Presenta una síntesis de resultados obtenidos en las investigaciones llevadas a cabo en este contexto, pero independientemente del caso de estudio, la propuesta de Borrazzo es una invitación a discutir el origen de patrones que a priori son considerados conductuales y que una aproximación desde el análisis tecnomorfológico, a veces, resulta insuficiente. Este trabajo representa una propuesta sobre un tema que fue abordado anteriormente desde distintos enfoques. Abordado desde una perspectiva de tafonomía actualista, los componentes fundamentales, y que se dejan ver en el trabajo, son los estudios naturalistas y experimentales, que se complementan enriqueciendo así el abordaje de este problema de equifinalidad. Creemos que este aporte, y desde este simposio se busca la incorporación sistemática de la tafonomía actualista a la investigación arqueológica para ajustar las interpretaciones sobre el registro lítico.

Borrazzo, Weitzel y Ceraso exploran como los artefactos líticos responden al pisoteo, diseñando un estudio experimental sobre artefactos de obsidiana en el trabajo titulado "Exploración experimental de los efectos del pisoteo sobre artefactos de obsidiana". En base a los datos obtenidos evalúan las frecuencias de fracturas y la existencia de variaciones en los valores del Potencial para la Fragmentación por Pisoteo (PFP) obtenidos en estudios previos. Es de destacar la importancia que le otorga este trabajo a la experimentación, cuyos datos 
se analizan a través de estadísticas descriptivas, test y un árbol de decisión. A partir de este estudio, las autoras y el autor, logran constatar las frecuencias de fracturas por pisoteo en distintos sustratos, las características de las fracturas y sus atributos dimensionales, y la posición de las mismas en distintas piezas. Consideramos que este trabajo constituye un aporte fundamental al estudio de la acción de los factores postdepositacionales en conjuntos líticos y posee un elevado potencial informativo, ya que aporta al conocimiento sobre los patrones de las fracturas en artefactos de obsidiana y otras materias primas. Es significativa, además, la contribución que se realiza sobre la ocurrencia de fracturas que podrían confundirse con fracturas intencionales.

Carballido Calatayud y Bellelli presentan "Historias de agua y fuego. Modificaciones del material lítico en sitios del bosque norpatagónico". Las autoras en este trabajo evalúan las incidencias de dos agentes de alteración sobre conjuntos líticos provenientes de excavación, el fuego producto de incendios forestales y la humedad en suelos producto de la acumulación de agua. Se presenta el análisis de tres casos ubicados en localizaciones diferentes del área boscosa al límite de los Parques Nacionales Nahuel Huapí y los Alerces. Este trabajo presenta un valioso aporte a la determinación de las alteraciones térmicas y su distribución en el espacio respecto de estructuras de combustión. No sólo eso, sino también las alteraciones producto del contacto con agua, las superficies húmedas y sus efectos sobre los materiales líticos. En este sentido, esta contribución llama la atención sobre el registro de tales alteraciones, la importancia de determinar su origen y los atributos característicos sobre los materiales.

El trabajo de Oria, Bártoli y Pal, "Aportes al estudio de procesos postdepositacionales en el ámbito lagunar. Sitio Arturo 4 (norte de Tierra del Fuego)", presenta un caso de estudio de conjuntos líticos en un ámbito lagunar desde una perspectiva tafonómica y geoarqueológica. Las autoras buscan comprender si el origen de los conjuntos estudiados se debe a la acción antrópica o a la dinámica lagunar, que presenta periodos de sequía estacionales. Para ello estudian variables tafonómicas específicas sobre los artefactos líticos recuperados, entre ellas la presencia de abrasión, pulido y/o fracturas, las cuales les permiten indagar sobre las preguntas planteadas. Los resultados que obtienen a partir del análisis realizado, les permite comprender mejor la historia formacional de los conjuntos estudiados, en la que además de la actividad antrópica intervinieron diversos procesos tafonómicos tales como la deriva hídrica o el congelamiento del sustrato. Este trabajo destaca la importancia que tienen los estudios postdepositacionales para evaluar la configuración de depósitos de artefactos líticos en contextos altamente dinámicos.

Carranza, Balirán, Bobillo y Sitzia con el trabajo titulado "Procesos de formación de conjuntos líticos: casos de estudio y abordajes metodológicos" presentan tres casos de estudio que, en áreas diferentes, comparten una perspectiva de abordaje tafonómica y experimental. Los autores desarrollan un abordaje metodológico para cada caso de estudio, con el fin de evaluar la incidencia de los agentes naturales sobre los conjuntos líticos. Distintas variables son relevadas, como la abrasión eólica y su intensidad sobre la superficie de los artefactos, que responden a diferentes preguntas que tienen que ver la diacronía en los eventos de talla y con la estabilidad de los conjuntos en distintos contextos geomorfológicos. En cuanto a la experimentación, los autores señalan la importancia de su implementación como vía para testear hipótesis y conocer la magnitud de las transformaciones de los conjuntos líticos. Los tres casos de estudio presentados remarcan cómo un mismo abordaje metodológico se implementa en casos de estudios diferentes, que, si bien comparten algunas características ambientales, su calibración y reconocimiento local son fundamentales.

Finalmente, el trabajo de Balirán "En busca de un acuerdo sobre aspectos básicos para el estudio tafonómico de conjuntos líticos", presenta una síntesis metodológica para el abordaje de un estudio tafonómico centrado en la tecnología lítica. Su trabajo hace un recorrido por las preguntas que deben formularse en cada paso de una investigación de este tipo y otorga algunas de las posibles respuestas. Como parte complementaria de esta síntesis la autora pone el foco en la experimentación como una vía necesaria para la contrastación de hipótesis que surgen de este tipo de estudios. Para ello repasa los recaudos metodológicos que deben seguirse a la hora de realizar un diseño experimental, de forma tal que sus resultados permitan la formulación de inferencias válidas. Finalmente presenta un caso de estudio a modo de ejemplo, que sigue los pasos del esquema de trabajo que plantea.

Los trabajos aquí presentados resaltan lo fundamental de conocer y estudiar los contextos de trabajo y los ambientes con sus variaciones. En este sentido, la integración en varios casos aquí presentados de los estudios de procesos de formación, el marco tafonómico y geoarqueológico ha potenciado el poder explicativo de los conjuntos tecnológicos analizados representan, sin lugar a duda, un avance en el abordaje de registro arqueológico lítico. 